\title{
Strategically equivalent contests
}

\author{
Subhasish M. Chowdhury • Roman M. Sheremeta
}

Published online: 17 May 2014

C The Author(s) 2014. This article is published with open access at Springerlink.com

\begin{abstract}
Using a two-player Tullock-type contest, we show that intuitively and structurally different contests can be strategically equivalent. Strategically equivalent contests generate the same best response functions and, as a result, the same equilibrium efforts. However, strategically equivalent contests may yield different equilibrium payoffs. We propose a simple two-step procedure to identify strategically equivalent contests. Using this procedure, we identify contests that are strategically equivalent to the original Tullock contest, and provide new examples of strategically equivalent contests. Finally, we discuss possible contest design applications and avenues for future theoretical and empirical research.
\end{abstract}

Keywords Rrent-seeking · Contest · Equivalence $\cdot$ Contest design

\begin{abstract}
An earlier version of this paper was circulated under the title "The Equivalence of Contests." We have benefitted from the helpful comments of anonymous referees, and Kyung Hwan Baik, Tim Cason, Subir Chakrabarti, Dan Kovenock, Sanghack Lee, John Lopresti, Stephen Martin, Ted Turocy, seminar participants at Indian Statistical Institute Calcutta, IUPUI, Kookmin University, Purdue University, the University of East Anglia and participants at the Midwest Economic Theory Meetings at OSU. The usual disclaimers apply.
\end{abstract}

\section{S. M. Chowdhury $(\varangle)$}

School of Economics, Centre for Behavioural and Experimental Social Science, and the ESRC Centre for Competition Policy, University of East Anglia, Norwich NR4 7TJ, UK e-mail: s.modak-chowdhury@uea.ac.uk

\section{R. M. Sheremeta}

Weatherhead School of Management, Case Western Reserve University,

Case Western Reserve University, 11119 Bellflower Road, Cleveland, OH 44106, USA

R. M. Sheremeta

Economic Science Institute, Chapman University, One University Drive, Orange, CA 92866, USA

e-mail: rms246@case.edu 
JEL Classification $\quad \mathrm{C} 72 \cdot \mathrm{D} 72 \cdot \mathrm{D} 74$

\section{Introduction}

A contest is a game in which players expend costly resources, such as effort, money, or time, in order to win a prize. Since the seminal papers of Tullock (1980) and Lazear and Rosen (1981), many different contests have been introduced to the literature. For example, Skaperdas (1992) studies contests where the final payoff depends on the residual resources and the prize. Chung (1996) and Kaplan et al. (2002) examine contests with effort-dependent prizes. Lee and Kang (1998) and Baye et al. (2005) study contests with rank-order spillovers. Although these contests are intuitively and structurally very different, they often share common links.

There are several studies that establish common links between different contests. For example, Che and Gale (2000) provide a link between a rank-order tournament of Lazear and Rosen (1981) and an all-pay auction of Hillman and Riley (1989); Baye et al. (2012) show the connection between the all-pay auction and pricing games (Varian 1980; Rosenthal 1980). Hirshleifer and Riley (1992) show how an R\&D race between two players which is modeled as a rank-order tournament is equivalent to a rent-seeking contest. ${ }^{1}$ Baye and Hoppe (2003) identify conditions under which research tournament models (Fullerton and McAfee 1999) and patent race models (Dasgupta and Stiglitz 1980) are strategically equivalent to the rent-seeking contest. These duality results permit one to apply results derived in the rent-seeking contest literature to the innovation, patent race, and rank-order tournament models, and vice versa.

In this paper, we show that intuitively and structurally different contests can be strategically and effort equivalent. We consider a two-player Tullock-type contest, where outcome-contingent payoffs are linear functions of prizes, own effort, and the effort of the rival. Under this structure, we identify strategically equivalent contests that generate the same best response functions and, as a result, the same equilibrium efforts. However, the strategically equivalent contests may yield different equilibrium payoffs.

It is important to emphasize that the aforementioned studies establish links between different families of contests, such as all-pay auctions, rent-seeking contests, and rankorder tournaments. The main result of this paper is conceptually different from the findings of the previous studies. In particular, we show that even within the same family of Tullock-type contests, different kinds of contests might produce the same best response functions and the same equilibrium efforts (although not necessarily the same payoffs).

\footnotetext{
1 Jia (2008) extends the result by proving a more general equivalence between a rank-order tournament and a rent-seeking contest. Fu and $\mathrm{Lu}$ (2012) shows that the rent-seeking contest can further include auctions with pre-investment (Tan 1992). Similarly, Cason et al. (2012) links the rent-seeking contest to a proportionalprize contest. Chowdhury (2009) demonstrates the connection between all-pay auctions (Siegel 2009) and capacity-constrained price contests (Osborne and Pitchik 1986; Deneckere and Kovenock 1996).
} 
Tullock (1980) introduced a contest model in which resources expended by a player improve the probability of winning the contest, but can never make the winning probability certain. These types of contests are characterized with high volume of noise in the outcome. Rent-seeking, legal disputes, and sports competitions are often modeled using the Tullock contest model. In a simple two-player lottery Tullock contest, the best response curves are inverted U-shaped, implying that best responses are first strategic complements and then strategic substitutes. It is also the case that a unique pure strategy Nash equilibrium exists, in which each player expends a quarter of the prize.

Since the seminal work by Tullock, numerous studies modified the original model to incorporate various structural and policy-related issues such as tax/subsidy (Glazer and Konrad 1999), endogenous prize (Chung 1996; Amegashie 1999), depreciation (Alexeev and Leitzel 1996), spillover (Chowdhury and Sheremeta 2011a), reimbursement (Matros and Armanios 2009), externality (Lee and Kang 1998), liability structure (Skaperdas and Gan 1995), and litigation issues (Farmer and Pecorino 1999) — to name a few (see Konrad 2009 for an extensive review). Although these models use the same framework of the Tullock contest, the final outcomes are often very different. To the best of our knowledge, no study tried to examine possible equivalence among the aforementioned models.

Introducing equivalence among Tullock-type contests is important for a number of reasons. First, there exists a substantial literature modeling the rules of the contest as an endogenous choice of a contest designer (Dasgupta and Nti 1998; Epstein and Nitzan 2006; Corchón and Dahm 2011; Polishchuk and Tonis 2013). A contest designer can choose the parameters of the model to maximize the total rent dissipation (as in the case of rent-seeking), or maximize the equilibrium highest effort (as in R\&D races), or minimize the total equilibrium effort (as in electoral races), or simply to enhance public welfare. Our results demonstrate that it is possible for a contest designer to achieve different goals using strategically equivalent contests. For example, the contest designer seeking Pareto improvement may choose a contest that generates the same equilibrium efforts, incurs the same costs, but results in higher expected payoffs for contestants. We show, in subsequent sections, that indeed such opportunity may exist. Under certain conditions, for example, a contest designer may prefer to implement a limited liability contest (Skaperdas and Gan 1995) than a contest that imposes full liability on contestants. Finally, certain contests may be not feasible (or too costly) to implement in the field due to regulatory restrictions and the possibility of collusion among contestants. However, such restrictions may not necessarily apply to other strategically equivalent contests. We show, for example, that a contest with endogenous valuation (Amegashie 1999) that may be hard to regulate, is equivalent to a contest with a simple taxation rule (Glazer and Konrad 1999).

The remainder of the paper is organized as follows. Section 2 describes the basic model; Sect. 3 specifies the definitions of equivalence and provides with the conditions to achieve them. Section 4 describes contests from literature that are strategically equivalent to the original Tullock contest, as well as introduces a set of modified Tullock-type contests that are strategically equivalent to each other. Section 5 concludes. 


\section{The model}

Following Baye et al. (2005); Baye et al. (2012) and Chowdhury and Sheremeta (2011a,b), we consider a two-player contest with two prizes. The players, denoted by $i$ and $j$, value the winning and the losing prizes as $W>0$ and $L \in \mathbb{R}$, with $W>L$. Players simultaneously and independently expend efforts $x_{i} \geq 0$ and $x_{j} \geq 0$. The probability of player $i$ winning the contest is defined by a lottery contest success function (Tullock 1980):

$$
p_{i}\left(x_{i}, x_{j}\right)= \begin{cases}x_{i} /\left(x_{i}+x_{j}\right) & \text { if } x_{i}+x_{j} \neq 0 \\ 1 / 2 & \text { if } x_{i}=x_{j}=0\end{cases}
$$

Contingent upon winning or losing, the payoff for player $i$ is a linear function of prizes, own effort, and the effort of the rival:

$$
\pi_{i}\left(x_{i}, x_{j}\right)=\left\{\begin{array}{ll}
W+\alpha_{1} x_{i}+\beta_{1} x_{j} & \text { with probability } p_{i}\left(x_{i}, x_{j}\right) \\
L+\alpha_{2} x_{i}+\beta_{2} x_{j} & \text { with probability } 1-p_{i}\left(x_{i}, x_{j}\right),
\end{array},\right.
$$

where $\alpha_{1}, \alpha_{2}$ are cost parameters $\left(\alpha_{1}<0, \alpha_{2} \leq 0\right)$, and $\beta_{1} \in \mathbb{R}, \beta_{2} \in \mathbb{R}$ are spillover parameters. We define the contest described by (1) and (2) as $\Gamma(i, j, \Omega)$, where $\Omega=\left\{W, L, \alpha_{1}, \alpha_{2}, \beta_{1}, \beta_{2}\right\}$ is a set of parameters. All parameters in $\Omega$ and the contest success function are common knowledge. Players are risk neutral, therefore, the expected payoff for player $i$ is

$$
E\left(\pi_{i}\left(x_{i}, x_{j}\right)\right)=\frac{x_{i}}{x_{i}+x_{j}}\left(W+\alpha_{1} x_{i}+\beta_{1} x_{j}\right)+\frac{x_{j}}{x_{i}+x_{j}}\left(L+\alpha_{2} x_{i}+\beta_{2} x_{j}\right),
$$

where $\left(x_{i}, x_{j}\right) \neq(0,0)$. For $x_{i}=x_{j}=0$, the expected payoff is $E\left(\pi_{i}\left(x_{i}, x_{j}\right)\right)=$ $(W+L) / 2 .^{2}$

Player $i$ 's best response is derived by maximizing $E\left(\pi_{i}\left(x_{i}, x_{j}\right)\right)$ with respect to $x_{i}$ :

$$
x_{i}^{\mathrm{BRF}}= \begin{cases}-x_{j}+\sqrt{\frac{\left\{\left(\alpha_{1}-\alpha_{2}\right)-\left(\beta_{1}-\beta_{2}\right)\right\} x_{j}^{2}-\{W-L\} x_{j}}{\alpha_{1}}} & \text { if } x_{j} \leq \frac{W-L}{\left\{\left(\alpha_{1}-\alpha_{2}\right)-\left(\beta_{1}-\beta_{2}\right)\right\}} \\ 0 & \text { otherwise }\end{cases}
$$

Chowdhury and Sheremeta (2011a) show that although the payoff function (3) is not globally concave, the first-order condition and the resulting best response function (4) are sufficient for an equilibrium to exist. The restriction needed for the best response function to be well defined, i.e., $x_{j} \leq \frac{W-L}{\left\{\left(\alpha_{1}-\alpha_{2}\right)-\left(\beta_{1}-\beta_{2}\right)\right\}}$, is weaker than the condition needed for the payoff function to be concave in the relevant region and as a result, when the best response is positive then solving the best response functions will give us an equilibrium. Moreover, under the appropriate restrictions, i.e., $\left(\beta_{2}-\alpha_{1}\right) \geq 0$

2 Risk neutrality is crucial, as elaborated in the discussion section, for closed form solutions and results of this analysis. If the players are not risk neutral, then it is possible that players exert different efforts in equilibrium (than the one derived under risk neutrality) and there are multiple equilibria (Cornes and Hartley 2012). 
and $-\left(3 \alpha_{1}+\alpha_{2}\right)-\left(\beta_{1}-\beta_{2}\right)>0$, there is a unique symmetric equilibrium defined by:

$$
x_{i}^{*}=x_{j}^{*}=x^{*}=\frac{(W-L)}{-\left(3 \alpha_{1}+\alpha_{2}\right)-\left(\beta_{1}-\beta_{2}\right)} .
$$

Given the symmetric equilibrium (5), the equilibrium payoff is

$$
E^{*}(\pi)=\frac{\left(\beta_{2}-\alpha_{1}\right)(W-L)}{-\left(3 \alpha_{1}+\alpha_{2}\right)-\left(\beta_{1}-\beta_{2}\right)}+L .
$$

The contest $\Gamma(i, j, \Omega)$, defined by (1) and (2), may also generate asymmetric equilibria. ${ }^{3}$ Since in the current study we focus only on the symmetric equilibrium, we impose further restriction $\left(5 \alpha_{1}-\alpha_{2}\right)-\left(\beta_{1}-\beta_{2}\right)>0$, derived by Chowdhury and Sheremeta (2011b), to guarantee the uniqueness of the equilibrium.

\section{Equivalent contests}

In this section, we define strategically equivalent contests and show the required parametric restrictions to obtain the equivalence. We start by providing a definition of strategic equivalence.

Definition 1 Contests are strategically equivalent if they generate the same best response functions.

This definition of strategic equivalence comes directly from Morris and Ui (2004) who provide a general characterization of best response equivalent games. It is, however, different from the definition used in Baye and Hoppe (2003) in which games are strategically equivalent when they generate the same expected payoff functions, and thus the same equilibrium payoffs. Here, we use a less restrictive definition of strategic equivalence, namely the best response equivalence. It is usually the case in the contest design literature that a contest designer chooses the rules of the contest to induce a specific behavior of contestants (Dasgupta and Nti 1998; Epstein and Nitzan 2006), while being indifferent towards the resulting payoffs of contestants. Thus, it seems appropriate to have a less restrictive definition of strategic equivalence that mainly relates to strategic behavior of contestants and not their payoffs. ${ }^{4}$

To demonstrate strategic equivalence, let us now consider two contests $\Gamma^{A}\left(i, j, \Omega^{A}\right)$ and $\Gamma^{B}\left(i, j, \Omega^{B}\right)$, where $\Omega^{k}=\left\{W^{k}, L^{k}, \alpha_{1}^{k}, \alpha_{2}^{k}, \beta_{1}^{k}, \beta_{2}^{k}\right\}$ for $k=A, B$. From equation (4), the necessary and sufficient condition for contests $\Gamma^{A}\left(i, j, \Omega^{A}\right)$ and

\footnotetext{
3 Chowdhury and Sheremeta (2011b) show that asymmetric equilibria, in which one player exerts very high effort and another player exerts very low effort can arise in strictly restrictive cases (such as when the marginal cost of losing the contest is substantially higher than the marginal cost of winning the contest). In this study, we focus on the more general case of symmetric equilibrium that allows for cleaner algebra, while not compromising on basic intuitions.

4 However, in many cases (e.g., for welfare and/or fairness purposes) a contest designer does care about the resulting payoffs of contestants. Therefore, using only the strict definition of strategic equivalence is not without costs, and one may use a more restrictive definition of strategic equivalence that also requires the equivalence of payoffs (see Definition 3).
} 
$\Gamma^{B}\left(i, j, \Omega^{B}\right)$ to be strategically equivalent, i.e., to have the same best response functions, is the following:

$$
\begin{gathered}
\frac{\left(\alpha_{1}^{A}-\alpha_{2}^{A}\right)-\left(\beta_{1}^{A}-\beta_{2}^{A}\right)}{\alpha_{1}^{A}}=\frac{\left(\alpha_{1}^{B}-\alpha_{2}^{B}\right)-\left(\beta_{1}^{B}-\beta_{2}^{B}\right)}{\alpha_{1}^{B}} \\
\text { and } \quad \frac{\left(W^{A}-L^{A}\right)}{\alpha_{1}^{A}}=\frac{\left(W^{B}-L^{B}\right)}{\alpha_{1}^{B}} .
\end{gathered}
$$

Intuitively, (7) describes the conditions for which the two best response functions become the same. The second condition of (7) essentially shows that the winning to losing prize difference, scaled by the winning marginal cost, needs to be the same. Whereas the first condition shows that the winning to losing marginal cost versus spillover difference (again scaled by the winning marginal cost) should be the same for the two strategically equivalent contests. Hence, it may be possible that both the marginal costs, as well as the spillover values in one contest are higher than the same in another contest, but still the two contests are strategically equivalent. It also reiterates the fact that only the winning and losing prize value differences, and not the absolute valuations, matter.

Next, we define effort equivalent contests.

Definition 2 Contests are effort equivalent if they result in the same equilibrium efforts.

From equation (5), the necessary and sufficient condition for contests $\Gamma^{A}\left(i, j, \Omega^{A}\right)$ and $\Gamma^{B}\left(i, j, \Omega^{B}\right)$ to be effort equivalent is the following:

$$
\frac{\left(W^{A}-L^{A}\right)}{-\left(3 \alpha_{1}^{A}+\alpha_{2}^{A}\right)-\left(\beta_{1}^{A}-\beta_{2}^{A}\right)}=\frac{\left(W^{B}-L^{B}\right)}{-\left(3 \alpha_{1}^{B}+\alpha_{2}^{B}\right)-\left(\beta_{1}^{B}-\beta_{2}^{B}\right)} .
$$

Intuitively, (8) shows that the winning and losing prize value differences scaled by winning to losing marginal cost versus spillover parameters need to be the same for the two contests to produce the same equilibrium effort.

Generally, strategic equivalence (Definition 1) is a stronger condition than effort equivalence (Definition 2) because it requires different contests to generate exactly the same best response functions, and as a consequence the same equilibrium efforts. However, given that in our analysis we impose restrictions to guarantee that only the unique and symmetric equilibrium (5) exists, strategic equivalence implies effort equivalence. ${ }^{5}$ It is also important to emphasize that without spillovers, effort equivalence is the same as the revenue equivalence, since revenue of a contest designer is simply the sum of all individual efforts (Baron and Myerson 1982; Moldovanu and Sela 2001). ${ }^{6}$

\footnotetext{
5 If two contests generate exactly the same best response functions, then the best response functions also intersect at the same point - generating the same equilibrium output.

6 In contests with spillovers there are different ways to define revenue, and thus effort equivalence may not imply revenue equivalence. For example, revenue can be defined as the sum of individual efforts and both positive and negative spillovers, or as the sum of efforts and only positive spillovers. Such alternative definitions of revenue would require different conditions for revenue equivalence. In this paper, however,
} 
In addition to strategic and effort equivalence, we also define payoff equivalent contests.

Definition 3 Contests are payoff equivalent if they generate the same expected payoffs.

From equation (6), the necessary and sufficient condition for contests $\Gamma^{A}\left(i, j, \Omega^{A}\right)$ and $\Gamma^{B}\left(i, j, \Omega^{B}\right)$ to be payoff equivalent, i.e., to generate the same equilibrium payoffs, is the following:

$$
\frac{\left(\beta_{2}^{A}-\alpha_{1}^{A}\right)\left(W^{A}-L^{A}\right)}{-\left(3 \alpha_{1}^{A}+\alpha_{2}^{A}\right)-\left(\beta_{1}^{A}-\beta_{2}^{A}\right)}+L^{A}=\frac{\left(\beta_{2}^{B}-\alpha_{1}^{B}\right)\left(W^{B}-L^{B}\right)}{-\left(3 \alpha_{1}^{B}+\alpha_{2}^{B}\right)-\left(\beta_{1}^{B}-\beta_{2}^{B}\right)}+L^{B} .
$$

Similar to (7) and (8), the equivalence condition (9) can be interpreted as the following: the losing prize is a certain prize, along with that there is a possibility to win the difference of the winning and losing prize, but with an associated cost. The first component in both sides of equation (9) shows the expected payoff, and the second component is the certain losing payoff. Understandably, the sum of the two is the same for two payoff equivalent contests.

It is easy to verify that strategic equivalence (Definition 1) does not automatically imply payoff equivalence (Definition 3). As we show in the next section, depending on the cost and spillover parameters in $\Omega$, one strategically equivalent contest can generate higher payoff than another.

Finally, to simplify our analysis, we assume that all alternative contests have the same winning prize and the same losing prize, i.e., $W^{A}=W^{B}=W$ and $L^{A}=$ $L^{B}=L$. This assumption is intuitive when the contest designer has specific predefined prizes which he can use to design a contest. ${ }^{7}$ Given this assumption, strategic equivalence condition (7) and effort equivalence condition (8) are simplified to the following condition:

$$
\beta_{2}^{A}-\beta_{1}^{A}-\alpha_{2}^{A}=\beta_{2}^{B}-\beta_{1}^{B}-\alpha_{2}^{B} \text { and } \alpha_{1}^{A}=\alpha_{1}^{B}
$$

In the rest of the paper, we follow a simple two-step procedure to find strategically equivalent contests to a particular baseline contest. First, we derive the best response function of the baseline contest as in Eq. (4). Second, from the best response function of the baseline contest we derive the restrictions needed, as in (10), for a more general family of contests to generate the same best response functions. This simple procedure is used throughout our analysis.

\section{Footnote 6 continued}

we focus only on effort equivalence since eliciting individual efforts are usually the main objective of a contest designer.

7 This specification is more restrictive than when the designer has the total prize value the same for two contests (i.e., $W^{A}+L^{A}=W^{B}+L^{B}$ ), but can allocate the winning and losing prize according to the contest. However, these two specifications converge when there is no losing prize (i.e., $L^{A}=L^{B}=0$ ). 


\section{Equivalent contests}

We begin with the original contest of Tullock (1980) as the baseline contest in Sect. 4.1, and describe contests from literature that are strategically equivalent to the Tullock contest. In Sect. 4.2, we introduce a set of modified Tullock-type contests that are strategically equivalent to each other.

\subsection{Original Tullock contest}

In the standard rent-seeking contest, introduced by Tullock (1980), there is no losing prize and regardless of the outcome of the contest, both players forgo their efforts. In such a case, the winning prize value $W>0, \alpha_{1}=\alpha_{2}=-1$, and the other parameters in $\Omega$ are zero. The payoff for player $i$ in case of winning or losing is

$$
\pi_{i}\left(x_{i}, x_{j}\right)= \begin{cases}W-x_{i} & \text { with probability } p_{i}\left(x_{i}, x_{j}\right) \\ -x_{i} & \text { with probability } 1-p_{i}\left(x_{i}, x_{j}\right)\end{cases}
$$

Using our notation, the Tullock contest is defined as $\Gamma(i, j,\{W, 0,-1,-1,0,0\})$. The resulting best response function in such a contest for player $i$ is

$$
x_{i}=-x_{j}+\sqrt{W x_{j}}
$$

For a generic contest $\Gamma\left(i, j,\left\{W, L, \alpha_{1}, \alpha_{2}, \beta_{1}, \beta_{2}\right\}\right)$ to be strategically equivalent to contest $\Gamma(i, j,\{W, 0,-1,-1,0,0\})$, according to condition (10), we need to impose the following restrictions: $\beta_{2}-\beta_{1}-\alpha_{2}=1, \alpha_{1}=-1$, and $L=0$. Such restrictions guarantee that the best response function (4) is exactly the same as the best response function (12). Therefore, by definition these contests are strategically equivalent.

One particularly interesting case arises when we put further restrictions $\beta_{1}=-1$ and $\alpha_{2}=\beta_{2}=0$. In such a contest, $\Gamma(i, j,\{W, 0,-1,0,-1,0\})$, the new payoff function is:

$$
\pi_{i}\left(x_{i}, x_{j}\right)= \begin{cases}W-x_{i}-x_{j} & \text { with probability } p_{i}\left(x_{i}, x_{j}\right) \\ 0 & \text { with probability } 1-p_{i}\left(x_{i}, x_{j}\right)\end{cases}
$$

Note that in (13), the winner fully reimburses the loser. This can be interpreted as the "Marshall system of litigation" (Baye et al. 2005) in which the winner pays his own legal costs and also reimburses all of the legal costs of the loser, whereas the standard Tullock contest can be interpreted as the "American system of litigation" in which each litigant pays its own legal expenses. ${ }^{8}$ It can easily be shown that the unique equilibrium for contests defined by (11) and (13) is the symmetric equilibrium with $x_{i}^{*}=x_{j}^{*}=W / 4$. Moreover, the expected payoff in both contests is exactly the same, $E^{*}(\pi)=W / 4$. Therefore, contests (11) and (13) are strategically, effort and payoff equivalent. This equivalence is surprising, since the two contests are intuitively and structurally very different. However, it has been also shown in an all-pay auction

$\overline{8}$ Also see Matros and Armanios (2009) and Yates (2011) for further examples of this type of contests. 
setting under incomplete information (Baye et al. 2005). Therefore, our results provide further evidence that Marshall and American systems of litigation are revenue (in our case, effort) and payoff equivalent. ${ }^{9}$ Furthermore, the robustness of the result shows that the seemingly unfair Marshall system of litigation indeed result in the same effort and payoff to litigants as the standard American system. Hence, it may not be necessary (under the restriction of risk neutrality) for an institution to shift from one to another system of litigation.

It is also straightforward to show that the "input spillover" contest of Chowdhury and Sheremeta (2011a) and Baye et al. (2012), where the effort expended by player $j$ partially affects player $i$ and vice versa, is strategically equivalent to the original Tullock contest. The spillover contest can be defined as $\Gamma(i, j,\{W, 0,-1,-1, \beta, \beta\})$, where $\beta \in(-1,1)$ is the input spillover parameter. This type of contest is motivated by spillover effects in R\&D innovation (D’Aspremont and Jacquemin 1988; Kamien et al. 1992). From strategic equivalence condition (10), one can see that for any value of $\beta$, the resulting best response function is exactly the same as in (11). Hence, the input spillover contest $\Gamma(i, j,\{W, 0,-1,-1, \beta, \beta\})$ is strategically equivalent to the original Tullock contest $\Gamma(i, j,\{W, 0,-1,-1,0,0\})$. This result suggests that if an $\mathrm{R} \& \mathrm{D}$ competition is modeled as a lottery contest, then the existence of symmetric spillovers may not affect the equilibrium. However, the "input spillover" contest is not payoff equivalent to the original Tullock contest, since condition (10) is not satisfied. It can be easily shown that a positive (negative) spillover provides a higher (lower) payoff to the players than the Tullock contest. Hence, our analysis gives further support, from a benevolent policymaker's point of view, to encourage contests with positive spillover and discourage contests with negative spillovers. Since in the R\&D contests positive spillovers are often related to the Intellectual Property Rights (IPR) issues, a designer might try to manipulate the spillover parameters such that the positive spillovers are high enough without damaging the IPR issues.

\subsection{Modified Tullock-type contests}

Researchers often use modified versions of the original Tullock contests in order to address specific questions such as taxes, subsidies, externalities, effort-dependent valuations, cost differences, etc. There are instances in the literature where two different Tullock-type contests are strategically equivalent to each other. Here, we briefly discuss some of these examples.

Chung (1996) assumes that the value of the winning prize depends on the total effort expenditures in the contest. A simple linear version of the Chung (1996) model would generate the following payoff function:

\footnotetext{
9 There are two structural differences between Baye et al. (2005) and this study. We use a Tullock CSF with complete information, whereas Baye et al. (2005) implement an all-pay auction CSF with incomplete information. In an all-pay auction, the player with the highest effort wins the contest with certainty, whereas in the Tullock contest, the player with the highest effort only has a higher probability of winning. Moreover, in an incomplete information setting, players do not know about the prize valuation (and other parameters) of its rival, but know only about the distribution, whereas in complete information setting everything is common knowledge.
} 


$$
\pi_{i}\left(x_{i}, x_{j}\right)= \begin{cases}W+a\left(x_{i}+x_{j}\right)-x_{i} & \text { with probability } p_{i}\left(x_{i}, x_{j}\right) \\ -x_{i} & \text { with probability } 1-p_{i}\left(x_{i}, x_{j}\right)\end{cases}
$$

Hence, (14) can be described as $\Gamma(i, j,\{W, 0, a-1,-1, a, 0\})$, where $a \in(0,1)$, and the best response function is

$$
x_{i}=-x_{j}+\sqrt{W x_{j} /(1-a)}
$$

Lee and Kang (1998) study a contest with externalities. In their model, the cost of effort decreases with the total effort expenditures. This contest can be captured by

$$
\pi_{i}\left(x_{i}, x_{j}\right)= \begin{cases}W-x_{i}+b\left(x_{i}+x_{j}\right) & \text { with probability } p_{i}\left(x_{i}, x_{j}\right) \\ -x_{i}+b\left(x_{i}+x_{j}\right) & \text { with probability } 1-p_{i}\left(x_{i}, x_{j}\right)\end{cases}
$$

Hence, (16) can be described as $\Gamma(i, j,\{W, 0, b-1, b-1, b, b\})$, where $b \in(0,1)$, and the best response function is

$$
x_{i}=-x_{j}+\sqrt{W x_{j} /(1-b)}
$$

When $a=b$ the best response functions (15) and (17) and the equilibrium effort expenditures in the two contests are exactly the same. This result indicates that some contests with endogenous prizes, as in Chung (1996), are strategically equivalent to contests with externalities, as in Lee and Kang (1998). Also note that, although both contests are strategically equivalent, they are not payoff equivalent. In particular, the contest defined by (16) results in higher expected payoff than the contest defined by (14), providing a clear Pareto ranking between the two contests. Hence, a benevolent contest designer, such as the government trying to maximize the total social welfare, may opt to choose a contest that elicits the same level of expenditures and, at the same time, results in Pareto improvement for both contestants.

Next, we consider a "limited liability" contest introduced by Skaperdas and Gan (1995), where the loser's payoff is independent of the efforts expended. ${ }^{10}$ The authors motivate this example by stating that contestants may be entrepreneurs who borrow money to spend on research and development and thus are not legally responsible in case of a loss. The loser of such a contest is unable to repay the loan and goes bankrupt. In such a case, $W>0, \alpha_{1}=-1$, and the other parameters in $\Omega$ are zero. The payoff is:

$$
\pi_{i}\left(x_{i}, x_{j}\right)= \begin{cases}W-x_{i} & \text { with probability } p_{i}\left(x_{i}, x_{j}\right) \\ 0 & \text { with probability } 1-p_{i}\left(x_{i}, x_{j}\right)\end{cases}
$$

The best response function for player $i$ is:

$$
x_{i}=-x_{j}+\sqrt{x_{j}^{2}+W x_{j}}
$$

\footnotetext{
10 Example of these kinds of contests can also be found in Matros and Armanios (2009).
} 
For a contest to be strategically equivalent to $\Gamma(i, j,\{W, 0,-1,0,0,0\})$ the required restrictions from (10) are $\beta_{2}-\beta_{1}-\alpha_{2}=0, \alpha_{1}=-1$, and $L=0$. When we impose further restrictions $\alpha_{2}=-1, \beta_{2}=-1$, and $\beta_{1}=0$ we obtain a contest with the following payoff function:

$$
\pi_{i}\left(x_{i}, x_{j}\right)= \begin{cases}W-x_{i} & \text { with probability } p_{i}\left(x_{i}, x_{j}\right) \\ -x_{i}-x_{j} & \text { with probability } 1-p_{i}\left(x_{i}, x_{j}\right)\end{cases}
$$

This contest can be interpreted as a "full liability" contest, since the loser has to pay in full the expenditures of both players. Note that although (18) is strategically equivalent to (20), the "full liability" contest is (by definition) more risky than the "limited liability" contest. In (18) players do not have to worry about what happens in the case of a loss, since they are not legally responsible. In contrast, the loser in (20) has to pay the expenditures of both players. Therefore, equivalence between (18) and (20) holds only under the assumption of risk neutrality. Moreover, it is easy to verify from (9) that contests (18) and (20) are not payoff equivalent. The equilibrium payoff in the "full liability" contest is $E^{*}(\pi)=0$ and in the "limited liability" contest it is $E^{*}(\pi)=W / 3$. This is another specific example in which a contest designer can step in, if he is interested in overall payoff. Since the two contests are effort equivalent, but the limited liability contest provides the players with a higher payoff, and presumably will need less monitoring than the full liability contest, a contest designer may be interested to implement a limited liability contest instead of a full liability contest.

Alexeev and Leitzel (1996) study a "rent-shrinking" contest $\Gamma(i, j,\{W, 0,-1,-1$, $-1,0\})$, where the winning prize value decreases by the total effort expenditures. From (10), a strategically equivalent contest would require $\beta_{2}-\beta_{1}-\alpha_{2}=2, \alpha_{1}=-1$ and $L=0$. A "lazy winner" contest $\Gamma(i, j,\{W, 0,-1,-2,0,0\})$ of Chowdhury and Sheremeta (2011a), in which the marginal cost of winning $\left(\alpha_{1}=-1\right)$ is lower than the marginal cost of losing $\left(\alpha_{2}=-2\right)$, definitely satisfies these restrictions. Moreover, the two contests are also payoff equivalent. The equivalence between the "rent-shrinking" and "lazy winner" contests enables the designer to achieve the same equilibrium rent dissipation using two alternative contests. Nevertheless, the "lazy winner" contest is, arguably, easier to implement and it is less susceptible to the collusion problem mentioned in Alexeev and Leitzel (1996).

In many cases, a contest designer can use different policy tools to implement a certain contest. Using the same procedure as before it can be shown that under certain restrictions, contests with endogenous valuations (Amegashie 1999), contests with differential cost structure (Chowdhury and Sheremeta 2011a), and contests with taxes (Glazer and Konrad 1999), are strategically equivalent. Specifically, Glazer and Konrad (1999) study a contest $\Gamma(i, j,\{(1-t) w, 0,-(1-t),-1,0,0\})$, in which a part of the rent seeker's non-negative profit is taxed with tax rate $t \in(0,1)$. Amegashie (1999) studies a contest $\Gamma(i, j,\{W, 0,-(1-m),-1,0,0\})$, in which the winner's prize value is a linear function of own effort spent. Chowdhury and Sheremeta (2011a)) study the "lazy winner" contest $\Gamma\left(i, j,\left\{W, 0, \alpha_{1}, \alpha_{2}, 0,0\right\}\right)$, in which the marginal cost of winning is lower than the marginal cost of losing, i.e., $\left|\alpha_{1}\right|<\left|\alpha_{2}\right|$.

Using condition (7), when $(1-t) w=W, \alpha_{1}-\alpha_{2}=t=m$, and $\alpha_{1}=(t-1)=$ $(m-1)$ then the three contests are strategically and effort equivalent. The first condition 
means that the take-home winning payoff in the contest with tax should be the same as the basic winning prize of the other two contests. The second condition implies that the tax rate in the tax contest should be same as the endogenous valuation margin in the endogenous valuation contest. Moreover, the difference between winning and losing marginal cost, which has the same effect in the lazy winner contest, should also be the same. Finally, and most intuitively, the marginal cost of winning in the lazy winner contest is same as the "effective" marginal costs of winning in the other two contests.

The equivalence between these three seemingly unrelated contests conveys an important message. It shows that the designer can either use policy tools, such as taxes, or contests with alternative cost structure to achieve the same objective, and it may be easier to implement the policy from one domain to another. Moreover, the three contests do not necessarily generate the same equilibrium payoffs. The equilibrium payoff (under the restriction of strategic equivalence) in Glazer and Konrad (1999) is $E^{*}(\pi)=(1-t)^{2} \mathrm{~W} /(4-3 t)$, in Amegashie (1999) it is $E^{*}(\pi)=(1-t) W /(4-3 t)$, and in Chowdhury and Sheremeta (2011a) it is $E^{*}(\pi)=(1-t) \mathrm{W} /(2-3 t)$. Hence, a contest designer, such as a government trying to maximize the social welfare, can achieve a Pareto improvement by choosing a specific contest structure that generates the highest payoffs for players yet results in the same equilibrium efforts. In specific, implementing a contest designed with endogenous valuation might be preferable to the designer than implementing a contest with taxation.

\section{Discussion}

In this paper, we use a two-player Tullock-type contest to show that intuitively and structurally different contests can be strategically equivalent. We define strategically equivalent contests as contests that generate the same best response functions. Under the assumption of a unique equilibrium, strategically equivalent contests are also effort equivalent. However, strategically equivalent contests may yield different equilibrium payoffs, and thus may not be payoff equivalent. We describe a simple two-step procedure to identify strategically equivalent contests. Using this procedure, we identify contests that are strategically equivalent to the original Tullock contest, and provide new examples of strategically equivalent contests.

We reestablish some existing results derived under alternative contest success functions and incomplete information, i.e., the equivalence of the American and Marshall systems of litigation. We also introduce new results, such as the equivalence between a standard Tullock contest and an input spillover contest, as well as the equivalence of a number of Tullock-type contests with endogenous valuations, spillovers, and differential cost structures.

Our findings contribute to the contest design literature by demonstrating how different strategically equivalent contests can be used to achieve the same objectives. A contest designer may choose to maximize the total rent dissipation, minimize equilibrium efforts, or simply enhance public welfare. Our results demonstrate that the contest designer can achieve these objectives by imposing appropriate restrictions on contest parameters. For example, we show that the two strategically and effort equivalent 
contests may yield different equilibrium payoffs. Hence, a contest designer seeking Pareto improvement may choose a contest that generates the same efforts, incurs the same costs, but results in higher expected payoffs for contestants.

It is important to understand the critical conditions required for the equivalence to hold in the field. Following the majority of the rent-seeking contests in the literature, we consider a two-player Tullock-type contest with linear cost and spillover structure under risk neutrality. The strategic equivalence results may not hold if we relax one or more of these assumptions. There are practical applications in which costs are convex (Moldovanu and Sela 2001), spillovers influence the payoff function in a non-linear manner (Kräkel 2004), or players are risk averse (Millner and Pratt 1991; Sheremeta and Zhang 2010). A different analysis of equivalence would be required in such cases.

There can also be behavioral factors that may influence individual decisions, but are not modeled in the current setting. For example, it has been shown in laboratory settings that contestants make mistakes (Sheremeta 2011), have incorrect judgments (Parco et al. 2005; Amaldoss and Rapoport 2009), and exhibit non-monetary utility of winning (Sheremeta 2010; Price and Sheremeta 2011). ${ }^{11}$ Some of these behavioral factors may distort individual behavior in strategically equivalent contests, and thus may break such equivalence.

There are many interesting extensions that call for future research, such as player asymmetry in terms of player specific parametric values or different winning and losing prizes in contests. It may also be interesting to apply the equivalence ideas to contests between groups. Nevertheless, the concept of strategic equivalence and the two-step procedure (described in Sect. 3) to obtain strategically equivalent contests would be still relevant for such analyses. Using the two-step procedure one could, for example, find equivalence conditions with more than two players, risk aversion, and non-linear cost/spillover structure. Such analyses, as well as the empirical tests of the equivalence in the laboratory are left for future research.

Open Access This article is distributed under the terms of the Creative Commons Attribution License which permits any use, distribution, and reproduction in any medium, provided the original author(s) and the source are credited.

\section{References}

Alexeev, M., \& Leitzel, J. (1996). Rent shrinking. Southern Economic Journal, 62, 620-626.

Amaldoss, W., \& Rapoport, A. (2009). Excessive expenditure in two-stage contests: Theory and experimental evidence. In F. Columbus (Ed.), Game theory: Strategies, equilibria, and theorems. Hauppauge, NY: Nova Science.

Amegashie, J. A. (1999). The number of rent-seekers and aggregate rent-seeking expenditures: An unpleasant result. Public Choice, 99, 57-62.

Baron, D., \& Myerson, R. (1982). Regulating a monopolist with unknown costs. Econometrica, 50, 911-930.

Baye, M., Kovenock, D., \& de Vries, C. G. (2005). Comparative analysis of litigation systems: An auctiontheoretic approach. Economic Journal, 115, 583-601.

11 For an extensive review of the experimental literature on contests see Dechenaux et al. (2014) and for a review of behavioral explanations see Sheremeta (2013). 
Baye, M. R., \& Hoppe, H. C. (2003). The strategic equivalence of rent-seeking, innovation, and patent-race games. Games and Economic Behavior, 44, 217-226.

Baye, M. R., Kovenock, D., \& de Vries, C. G. (2012). Contests with rank-order spillovers. Economic Theory, $51,350-351$.

Cason, T. N., Masters, W., Sheremeta, R. M. (2012). Winner-take-all and proportional-prize contests: Theory and experimental results. Chapman University, ESI Working Paper.

Che, Y. K., \& Gale, I. (2000). Difference-form contests and the robustness of all-pay auctions. Games and Economic Behavior, 30, 22-43.

Chowdhury, S. M. (2009). The all-pay auction with non-monotonic payoff. Centre for Competition Policy, University of East Anglia, Working Paper 10-16

Chowdhury, S. M., \& Sheremeta, R. M. (2011a). A generalized Tullock contest. Public Choice, 147, 413420.

Chowdhury, S. M., \& Sheremeta, R. M. (2011b). Multiple equilibria in Tullock contests. Economics Letters, $112,216-219$.

Chung, T. Y. (1996). Rent-seeking contest when the prize increases with aggregate efforts. Public Choice, 87, 55-66.

Corchón, L., \& Dahm, M. (2011). Welfare maximizing contest success functions when the planner cannot commit. Journal of Mathematical Economics, 47, 309-317.

Cornes, R., \& Hartley, R. (2012). Risk aversion in symmetric and asymmetric contests. Economic Theory, $51,247-275$.

D'Aspremont, C., \& Jacquemin, A. (1988). Cooperative and noncooperative R\&D in duopoly with spillovers. American Economic Review, 78, 1133-1137.

Dasgupta, A., \& Nti, K. (1998). Designing an optimal contest. European Journal of Political Economy, 14, 587-603.

Dasgupta, P., \& Stiglitz, J. (1980). Uncertainty, industrial structure, and the speed of R\&D. Bell Journal of Economics, 11, 1-28.

Dechenaux, E., Kovenock, D., \& Sheremeta, R. M. (2014). A survey of experimental research on contests, all-pay auctions and tournaments. Experimental Economics.

Deneckere, R. J., \& Kovenock, D. (1996). Bertrand-Edgeworth duopoly with unit cost asymmetry. Economic Theory, 8, 1-25.

Epstein, G. S., \& Nitzan, S. (2006). The politics of randomness. Social Choice of Welfare, 27, 423-433.

Farmer, A., \& Pecorino, P. (1999). Legal expenditure as a rent-seeking game. Public Choice, 100, $271-288$.

$\mathrm{Fu}, \mathrm{Q}$., \& Lu, J. (2012). Micro foundations of multi-prize lottery contests: A perspective of noisy performance ranking. Social Choice and Welfare, 38, 497-517.

Fullerton, R. L., \& McAfee, R. P. (1999). Auctioning entry into tournaments. Journal of Political Economy, $107,573-605$.

Glazer, A., \& Konrad, K. (1999). Taxation of rent-seeking activities. Journal of Public Economics, 72, 61-72.

Hillman, A., \& Riley, J. G. (1989). Politically contestable rents and transfers. Economics and Politics, 1, 17-40.

Hirshleifer, J., \& Riley, J. G. (1992). The analytics of uncertainty and information. New York: Cambridge University Press.

Jia, H. (2008). A stochastic derivation of the ratio form of contest success functions. Public Choice, 135, $125-130$.

Kamien, M. I., Muller, E., \& Zang, I. (1992). Research joint ventures and R\&D cartels. American Economic Review, 82, 1293-1306.

Kaplan, T., Luski, I., Sela, A., \& Wettstein, D. (2002). All-pay auctions with variable rewards. Journal of Industrial Economics, 50, 417-430.

Konrad, K. (2009). Strategy and dynamics in contests. Oxford: Oxford University Press.

Kräkel, M. (2004). R\&D spillovers and strategic delegation in oligopolistic contests. Managerial and Decision Economics, 25, 147-156.

Lazear, E., \& Rosen, S. (1981). Rank-order tournaments as optimum labor contracts. Journal of Political Economy, 89, 841-864.

Lee, S., \& Kang, J. (1998). Collective contests with externalities. European Journal of Political Economy, 14, 727-738.

Matros, A., \& Armanios, D. (2009). Tullock's contest with reimbursements. Public Choice, 141(1-2), 49-63. 
Millner, E. L., \& Pratt, M. D. (1991). Risk aversion and rent-seeking: An extension and some experimental evidence. Public Choice, 69(1), 81-92.

Moldovanu, B., \& Sela, A. (2001). The optimal allocation of prizes in contests. American Economic Review, 91, 542-558.

Morris, S., \& Ui, T. (2004). Best response equivalence. Games and Economic Behavior, 49, 260-287.

Osborne, M., \& Pitchik, C. (1986). Price competition in a capacity-constrained duopoly. Journal of Economic Theory, 38, 238-260.

Parco, J. E., Rapoport, A., \& Amaldoss, W. (2005). Two-stage contests with budget constraints: An experimental study. Journal of Mathematical Psychology, 49(4), 320-338.

Polishchuk, L., \& Tonis, A. (2013). Endogenous contest success functions: A mechanism design approach. Economic Theory, 52, 271-297.

Price, C. R., \& Sheremeta, R. M. (2011). Endowment effects in contests. Economics Letters, 111, $217-219$.

Rosenthal, R. (1980). A model in which an increase in the number of sellers leads to a higher price. Econometrica, 48, 1575-1580.

Sheremeta, R. M., \& Zhang, J. (2010). Can groups solve the problem of over-bidding in contests? Social Choice and Welfare, 35, 175-197.

Sheremeta, R. M. (2010). Experimental comparison of multi-stage and one-stage contests. Games and Economic Behavior, 68, 731-747.

Sheremeta, R. M. (2011). Contest design: An experimental investigation. Economic Inquiry, 49, 573-590.

Sheremeta, R. M. (2013). Overbidding and heterogeneous behavior in contest experiments. Journal of Economics Surveys, 27, 491-514.

Siegel, R. (2009). All-pay contests. Econometrica, 77, 71-92.

Skaperdas, S. (1992). Cooperation, conflict, and power in the absence of property rights. American Economic Review, 82, 720-739.

Skaperdas, S., \& Gan, L. (1995). Risk aversion in contests. Economic Journal, 105, 951-962.

Tan, G. (1992). Entry and R\&D costs in procurement contracting. Journal of Economic Theory, 68, 41-60.

Tullock, G. (1980). Efficient rent seeking. In James M. Buchanan, Robert D. Tollison, \& Gordon Tullock (Eds.), Toward a theory of the rent-seeking society (pp. 97-112). College Station, TX: Texas A\&M University Press.

Varian, H. (1980). A model of sales. American Economic Review, 70, 651-659.

Yates, A. J. (2011). Winner-pay contests. Public Choice, 147, 93-106. 